\title{
Wondrous Stethoscope: A Potential Disseminator of Pathogens in Health- Care Settings
}

\author{
Iqbal Akhtar Khan ${ }^{1 *}$ and Hamza Iltaf Malik ${ }^{2}$ \\ ${ }^{1}$ Independent Scholar, Lahore-54792, Pakistan. \\ ${ }^{2}$ Northampton General Hospital, Cliftonville, Northampton, NN1 5BD, United Kingdom.
}

*Corresponding author: Iqbal Akhtar Khan, Independent Scholar, Lahore-54792, Pakistán. Email <profiakhan@gmail.com>

Received date: September 02, 2021; Accepted date: September 11, 2021; Published date: October 01 , 2021

Citation: Iqbal A. Khan and Hamza I. Malik. (2021). Wondrous Stethoscope: A Potential Disseminator of Pathogens in Health-Care Settings. J Clinical Research and Reports, 9(2); DOI:10.31579/2690-1919/199

Copyright: ( 2021 , Iqbal Akhtar Khan. This is an open access article distributed under the Creative Commons Attribution License, which permits unrestricted use, distribution, and reproduction in any medium, provided the original work is properly cited.

\begin{abstract}
Stethoscope, the foundational clinical tool of medical profession, has been found to be a potential disseminator of infections in the healthcare settings (HAIs). Unfortunately, despite recognition of magnitude of the problem, its disinfection is an under-recognized, under-scored and grossly overlooked issue.

The three life savior words "Wash your hands" were uttered, for the first time, by Hungarian Obstetrician Ignaz Semmelweis (1818-1865) at the podium of The Vienna Medical Society's lecture hall on the historic day of May 15, 1850. Today, adequate hand hygiene has been recognized to be the single most important, feasible, doable, and least expensive tool in reducing the increasing toll of HAIs and the spread of antimicrobial resistance. However, efficacy of such a program would be undermined if the healthcare workers (HCWs) continue using unclean stethoscopes which have been found to harbor the same pathogens as on the hands of HCWs.

WHO's "Clean Care is Safer Care" guidelines promote hand hygiene before touching a patient. Likewise, the stethoscopes should be disinfected "before use on each patient". The resultant synergistic effect would prevent the dissemination of identical pathogens among patients and the care of "clinician's third hand" would certainly reduce burden of HAIs in healthcare settings.
\end{abstract}

Key Words: stethoscope; auscultation; stethoscope contamination; clinician's third hand; HAIs; hand hygiene

\section{Introduction}

"The stethoscope is the most prominent and enduring symbol of the interaction and bond between the physician and the patient. It is truly the clinician's third hand and is at the heart of all physical examinations. Its ability to provide rapid diagnostic and prognostic information is unsurpassed".

Alan Maisel, Professor Emeritus at the University of California, San Diego

The stethoscope was invented in 1816, at the Necker-Enfants Malades Hospital, by a French physician and musician René-Théophile-Hyacinthe Laennec (1781-1826), justifiably called "Father of Chest Medicine". His skill of carving his own wooden flutes led him to invent this marvelous device. The term "stethoscope" (looking into thorax), which he coined, has been traced to two Greek words: stethos (chest) and skopein (to view or see). He also called his method of using stethoscope "auscultation", from "auscultare" (listen). The process, used to listen cardiac sounds, lung sounds, and bowel sounds is not only cost effective, but it can be repeated as often as necessary. This ubiquitous, foundational clinical tool, with over 5.5 billion annual auscultations in the United States alone [1], functions as the "Clinician's Third Hand" [2].

Unfortunately, this wondrous device has been found to be a potential vector of healthcare associated infections (HAIs), if the required decontamination is ignored or is sub-optimal. There is growing evidence that bacteria can transfer from the skin of the patient to the stethoscope and from the stethoscope to the skin [3], resulting in an iatrogenic disease [4]. Studies have demonstrated a high frequency of notorious pathogens cultured from the stethoscope that may include methicillin-resistant Staphylococcus aureus (MRSA), Vancomycin-resistant Enterococcus (VRE) and Clostridium difficile causing significant morbidity and mortality [5]. The preponderance of MRSA, in majority of the studies, led Chilean researchers remark "Stethoscope or staphyloscope: Potential vector in nosocomial infections" [6]

\section{Infections acquired in Health-care Settings}

"Hospital-acquired infections result from "flawed" processes of care and hygiene, not from the treatment of sicker patients" [7]. 
As estimated by the WHO, healthcare-associated infections, or infections acquired in healthcare settings are the most frequent adverse event in healthcare delivery worldwide, affecting hundreds of millions of patients each year, leading to significant mortality and financial losses for health systems [8]. Unfortunately, despite multiple interventional strategies, there is a hidden, cross-cutting concern that no institution or country can claim to have solved as yet [9].

Three seemingly different terms, for the aforesaid infections, have been used in literature to convey similar meanings. To avoid any confusion, following definitions need to be clearly understood.

\section{Hospital-acquired Infection (HAI)}

- It is a localized or systemic condition that:

- $\quad$ results from adverse reaction to the presence of an infectious agent(s) or its toxin(s) and

- was not present or incubating at the time of admission to the hospital [7]

\section{Nosocomial Infection (NI)}

This term has been derived from two Greek words "nosos" (disease) and "komeion" (to take care of). In general, infections that occur more than 72 hours after admission and within 10 days after hospital discharge are defined as nosocomial. The time frame is modified for infections that have incubation period less than 72 hours (e.g., gastroenteritis caused by Norwalk virus) or longer than 10 days (e.g., hepatitis A). Surgical site infections are called nosocomial if the infection occurs within 30 days after the operative procedure or within 1 year if a prosthetic device or foreign material is implanted [10].

\section{Healthcare-associated Infection (HAI)/(HCAI)}

An infection that develops in a patient who is cared for in any setting where healthcare is delivered (e.g., acute care hospital, chronic care facility, ambulatory clinic, dialysis center, surgicenter, home) and is related to receiving healthcare (i.e., was not incubating or present at the time healthcare was provided). In ambulatory or home settings, HAI would apply to any infection that is associated with a medical or surgical intervention performed in those settings [11].

When contracted outside a healthcare setting (for example, in the community) and brought in by patients, staff or visitors and transmitted to others (for example, norovirus) is also included in the definition [12]. They also include infections acquired by patients in the hospital or facility but appearing after discharge, and occupational infections among staff [8].

They are abbreviated "HAI" in United States [11] and China [13] while "HCAI" in United Kingdom [12], Ireland [3], and Chile [6].

In the Briefing Paper by The National Institute for Health and Care Excellence (NICE), it was concluded that the six most common types of HCAIs in 2011, which accounted for more than $80 \%$ of all healthcareassociated infections, were respiratory tract infections (pneumonia, $22.8 \%$ ), urinary tract infections (17.2\%), surgical site infections (15.7\%), clinical sepsis (10.5\%), gastrointestinal infections $(8.8 \%)$, and bloodstream infections (7.3\%) [12]. HAIs represent a serious care problem for certain categories of patients including but not limited to ICU patients, those with immune deficiency or suppression, those on chemotherapy, recipients of organ transplants and diabetics.

Healthcare personnel (HCP) or Healthcare workers (HCW) refer to all persons, paid and unpaid, working in healthcare settings who have the potential for exposure to patients and/or to infectious materials, including body substances, contaminated medical supplies and equipment, contaminated environmental surfaces, or contaminated air. HCP include, but are not limited to, physicians, nurses, nursing assistants, therapists, technicians, emergency medical service personnel, dental personnel, pharmacists, laboratory personnel, autopsy personnel, students and trainees, contractual personnel, home healthcare personnel, and persons not directly involved in patient care (e.g., clerical, dietary, house-keeping, laundry, security, maintenance, billing, chaplains, and volunteers) but potentially exposed to infectious agents that can be transmitted to and from them and patients [14].

\section{Stethoscope: A Vector of Infectious Diseases}

"..............However, hidden in this ubiquitous healing tool is the potential for patient harm with inappropriate use, specifically as a means to transmit infectious disease" [15].

The stethoscope, a universal foundational tool of medical profession, is in constant use by HCWs for a comprehensive evaluation of various medical conditions through auscultation of the chest and abdomen. Various studies confirm that it could be a vector for cross-transmission of virulent organisms. The colonizing pathogens may be transmitted to the patient's skin after as few as 3 seconds of contact [16]. Since the typical auscultation procedures involve several minutes of contact with the skin, there are ample opportunities for transference of pathogens [17].

Tschopp et al have demonstrated that the stethoscope contamination following a single physical examination is not negligible and is associated with the level of contamination of the patient's skin [18]. In a structured prospective study, at a Swiss university teaching hospital, the contamination level of the stethoscope was substantial after a single physical examination and comparable to the contamination of parts of the physician's dominant hand [19]. It is important to note that the level of contamination of different parts of stethoscope is not the same. Diaphragms of stethoscopes are known to be the second most contaminated area after the fingertips, even after single physical examination [19]. However, a United States study has shown that up to $100 \%$ of diaphragms may be contaminated [20]. The pathogens cultured from physician's fingers are duplicated on the diaphragm, [21]. Besides the diaphragm, other parts of the stethoscope could be contaminated, such as plastic earpieces, which may remain colonized in spite of cleansing [22].

In a Nepalese study, contamination of the diaphragms $72.1 \%$ was higher compared to earpiece $66.2 \%$ and bells $58.1 \%$ [23]. In a United States study urethane rim, common to the stethoscopes was the most heavily burdened surface; mean concentrations exceeding the HAI's acquisition concentration $\left(5 \mathrm{CFU} / \mathrm{cm}^{2}\right)$ by at least $25 \times$ [24]. In a meta-analysis, by O'Flaherty, the mean rate of stethoscope contamination, across 28 studies, was $85 \%$ (range: $47-100 \%$ ). The potentially pathogenic organisms, cultured from stethoscopes, included: Staphylococcus aureus, Pseudomonas aeruginosa, VRE and Clostridium difficile [3].

In a United States study, where cultures were obtained from 200 stethoscopes from four area hospitals and outpatient clinics in Houston, Texas, $80 \%$ were found contaminated with microorganisms. Majority of the isolated ones were gram-positive bacteria, primarily Staphylococcus species. The $58 \%$ of the Staphylococcus species that were isolated, including four (17\%) of 24 Staphylococcus aureus isolates, were MRSA [25].

In a study carried out at a Brazilian tertiary care hospital on 300 randomly selected stethoscopes, $87 \%$ were found to be contaminated with single or multiple organisms predominantly Staphylococcus (58.6\%), Staphylococcus negative coagulase $(51 \%)$, yeast $(49.3 \%)$, Sarcina $(21.3 \%)$, and Bacillus spp (15\%). Other organisms isolated in lower numbers but of great clinical importance were Pseudomonas putida, Klebsiella pneumonia and Acinetobacter spp [26]. Aerobic and anaerobic 
bacterial cultures were performed on 40 randomly selected stethoscopes, in a study conducted at University of Michigan Medical Center. Eleven genera and species of bacteria were isolated with coagulase negative staphylococcus present in $100 \%$ of stethoscopes and Staphylococcus aureus on $38 \%$ [16].

Bernard et al reported recovery of up to 5 different bacterial species from the membrane of the $66 \%$ of the stethoscopes, in a study conducted in Hospitale Saint Joseph Paris France. Whereas 54\% were colonized with $>20$ colony forming units (CFU) per membrane, $18 \%$ carried $>100 \mathrm{CFU}$ (heavily colonized). In total, $72 \%$ stethoscopes tested did not meet the authorized norms of cleanliness (French Normalization Agency: bacterial carriage $<5 \mathrm{CFU} / \mathrm{cm} 2$ or $20 \mathrm{CFU}$ membrane) [27].

In a systematic review, by Queiroz et al, more than $50 \%$ of the analyzed stethoscopes were contaminated with some type of bacteria. Coagulasenegative Staphylococcus spp., Staphylococcus aureus, Acinetobacter spp., Pseudomonas spp., and Klebsiella pneumonia were the most recurrent pathogens. Besides that, multi-resistant strains were also isolated, highlighting resistance to Ampicillin and Clindamycin [28].

Although stethoscopes were contaminated in all areas in a United States study, those from the pediatric medical setting were contaminated less frequently than those from other hospital areas $(\mathrm{P}=.009)$ [25]. Conversely, in a pediatric community clinic, in Israel, all the 55 stethoscopes (included in the study) were found to harbor single or multiple organisms including Sarcinia lutea, Diphtheroids, Bacillus spp and other gram negatives. Staphylococcus aureus were isolated from $54.5 \%$ of which $13.3 \%$ were MRSA [22]. In a Nigerian study, a higher prevalence of stethoscope contamination was observed among those from the ICU (66.7\%), the VIP unit (50\%), and the antenatal unit (37.5\%). The main isolates were Staphylococcus aureus (44.4\%) and Escherichia coli $(50 \%)$. The antibiotic sensitivity assessment indicated that the bacterial isolates were resistant to nearly all the antibiotics tested [29]. In a crosssectional Nepalese study, on stethoscopes of 122 HCWs (wards $41.8 \%$, OPD $35.2 \%$, ICU $23 \%$ ), the bacterial load varied, with a minimum number of 9 colonies from a stethoscope sampled from the anesthesia department and a maximum 60 colonies from surgery ward and ICU [23].

\section{Disinfecting practices}

"Despite the recognition or reminder of the stethoscope as a vector for infectious disease, healthcare providers may not be allowed to spend enough the time between patient examinations to diligently clean their stethoscopes" [15].

Disinfection of stethoscope is an under-recognized, under-scored and grossly overlooked issue. This is partly because it is not taught or promoted to the same extent as hand hygiene [30].

Unfortunately, there is notable gap between beliefs and practices. In an anonymous online survey of nurses, nurse practitioners, and physicians at a United States pediatric hospital, from amongst 1401 respondents, 76\% believed that stethoscopes could transmit infection, but only $24 \%$ reported cleaning their scopes regularly [31]. A cross-sectional survey of HCWs was conducted in two community teaching hospitals of United States, to assess beliefs and practices related to cleaning of their stethoscope. Whereas $93 \%$ believed the role of stethoscopes in transmission of infection, only $29 \%$ reported cleaning after every use [32]. In a Pakistani descriptive cross-sectional study of 243 HCWs (consultants, residents, final-year medical students, and nursing staff), $86.4 \%$ were aware of stethoscopes as a source of HAIs. However, only $9.5 \%$ cleaned their stethoscope per patient, $20.6 \%$ did it daily, $19.8 \%$ did it weekly, $16.9 \%$ did it monthly, $14.9 \%$ did it six-monthly while $28.4 \%$ respondents had never cleaned their stethoscope. Of note, $99.2 \%$ believed that there were no accountability criteria set for the assessment of the cleanliness of stethoscopes in their hospitals [33].
In a facility-based cross-sectional study carried out on 546 HCWs (physicians, health officers, nurses, midwives, and anesthesiologist) included from 21 healthcare facilities in Addis Ababa, Ethiopia, it was found that only $39.7 \%$ were disinfecting their stethoscope after single use [34]. In a US observational, cross-sectional, anonymous study of patientprovider interactions, assessing $\mathrm{HCWs}$ ' frequency and methods of stethoscope disinfection practices, the CDC guidelines were followed in less than $4 \%$ of encounters. In $82 \%$ of encounters, no disinfection was practiced at all [35].

Disinfection of the stethoscopes, even if done regularly, may be incomplete. In a cross-sectional study carried out in Faculty of Medicine, University of Belgrade, Serbia, it was found that the diaphragm was most commonly cleaned, while the flexible tubing was the least commonly cleaned area [36].

The physicians' stethoscopes generally had a higher bacterial load than nurses' stethoscopes in the studies conducted in United States [25] and in Ethiopia [34]. This explains Sahiledengle's observation that the odds of stethoscope disinfection were likely to be reduced by $79 \%$ among physicians than nurses [34].

In their assessment of frequency and methods of disinfection, perceptions of contamination, and barriers to disinfection, Muniz et al identified 6 factors [31]:

- Lack of materials on hand

- $\quad$ Lack of visual reminders

- Concern about stethoscope damage

- Lack of time

- Lack of reminders from colleagues

- Difficulty of task

Interestingly, some HCWs suffer from "Omo syndrome", a belief that they are always super clean and sterile [37]. Despite their best intentions, the HCWs, at times, act as vectors of disease, disseminating new infections among their patients.

\section{How to Disinfect?}

"The choice of the method to disinfect stethoscope depends on effectiveness, availability, price, easy to use and common practice. The failure of disinfection methods does not seem to be due to the lack of effectiveness of what is used, but rather to a lack of regularity in the use of the products" [38].

The Spaulding Classification of Equipment \& Medical Devices, grades Stethoscope as a "noncritical medical device" (ie, in contact with intact skin, no bodily fluids). In the majority of cases, stethoscopes are used on intact skin and so the CDC recommendations suggest to disinfect it for "each patient or once daily or once weekly", whereas in the case of semicritical contact, as in the case of use on skin that is not intact (e.g., trauma), stethoscopes should be disinfected "before use on each patient" for at least 1 minute after each patient interaction using an alcohol or bleach-based disinfectant [39]. The practice of disinfection after every use has a potential impact of reducing transmission of HAIs [40]. It would be a preferable and acceptable strategy to disinfect the stethoscope while having a discussion with the patient.

The disinfectants, used to decontaminate stethoscopes, could be categorized in chemical and physical methods. 
i. Chemical methods include disinfection with alcohol, triclosan, sodium hypochlorite, chlorhexidine, and benzalkonium chloride.

In the healthcare setting, "alcohol" refers to two water-soluble chemical compounds, ethyl alcohol (ethanol) and isopropyl alcohol (IPA), the optimum germicidal concentration being $60-90 \%$ solutions in water. Both $90 \%$ ethanol and IPA were found equally effective as decontaminant in a study, conducted by Raghubanshi et al [41]. Mehta et al [42] found that both IPA wipes and Ethanol-Based Hands Sanitizer (EBHS) were effective, but the reduction of the bacterial count with the wipes was significantly greater than with the EBHS $(\mathrm{p}=0.00)$. The various formulations (liquid, gel, foam, alcohol-soaked wipes and EBHS or alcohol-based hand rub (ABHR) can be used according to preferences, availability and cost. The use of disinfectant wipes is a practical and fast method for decontaminating stethoscopes.

In a randomized double blind study of 100 stethoscopes, a positive culture was found in $90 \%$ before cleaning, which improved to $28 \%$ after immediate use of IPA as a cleaning method, and continued to improve down to $25 \%$ after 5 days of daily cleaning. However, without continuous cleaning, the positive cultures increased again to $95 \%$ of stethoscopes in 5 days [43].

Hydrogen peroxide wipes are also widely used to disinfect stethoscopes because of bactericidal, virucidal, sporicidal, and fungicidal properties. In a study conducted in medical ICU at the Hospital of the University of Pennsylvania, vigorously wiping the diaphragm with a hydrogenperoxide decreased contamination of half the stethoscopes to the level of a brand-new clean stethoscope, while the rest still had considerable reductions in the total amount of bacteria [40]. In a United States study, Holleck et al demonstrated that alcohol pads, alcohol-based hand rub, and hydrogen peroxide disinfectant wipes were equivalent in CFU reduction [44].Leprat et al have demonstrated the efficiency of wipes impregnated with benzalkonium. In their study, $100 \%$ decontamination was found [45].

In an Italian matched cross-over study involving three hospitals in Siena Province, 74 stethoscopes were analysed, including shared (47) and personal (27) ones. A putty compound containing $29 \%$ ethanol, purified water $51 \%$, guar $6 \%$, glycerine $7 \%$, and minor quantity of other substances such as boric acid, colorants and odorants having a malleable elastic consistency was used; it adheres, removes dirt, and disinfects at the same time. It was demonstrated that after cleaning the percentage reduction in CFUs in all samples was $99.8 \%$ for total bacterial counts (TBC) at $36^{\circ} \mathrm{C}$ and $99.9 \%$ for $\mathrm{TBC}$ at $22^{\circ} \mathrm{C}$ [46].

In the prevailing healthcare environments, alcohol-based wipes or hydrogen peroxide wipes are the most practical tools for effectively decontaminating stethoscopes. However, the integrity of stethoscopes needs to be checked after disinfection because alcohol scrubbing and turning can loosen and detach the ear tip pieces [47]. There is a case report from University of Hong Kong teaching hospital where the bare metal ear tip acted like a bevel to traumatize the right external auditory canal of the physician examining a patient [47].

\section{ii. Physical methods}

It is well known that solid copper and alloys containing > 60\% copper by weight have the property to kill bacteria to the touch [24]. A structured prospective trial involving $21 \mathrm{HCWs}$ was conducted at a US pediatric emergency division and an adult medical ICU located in tertiary care facilities. The mean aerobic colony counts (ACCs) collectively recovered from all stethoscope surfaces fabricated from the U.S. Environmental Protection Agency-registered antimicrobial copper alloys (AMCus) were found to carry significantly lower concentrations of bacteria than their control equivalents. Absence of recovery of bacteria from the $\mathrm{AMCu}$ surfaces $(66.3 \%)$ was significantly higher $(\mathrm{P}<.00001)$ than the control surfaces $(22.4 \%)$ [24].

Antimicrobial stethoscope covers impregnated with silver ions have been developed to reduce the surface colonization of pathogens. However, in a United States study, Wood et al have questioned the efficacy of such covers. They evaluated the utility of diaphragms' cover infused with silver ions by analyzing 74 stethoscopes ( 37 with cover and 37 without cover). Astonishingly, it was found that the bacterial load was greater in the surfaces of stethoscopes with cover than in those without cover, especially if the cover was used more than the time suggested by the manufacturer (one week) [20]. In fact, a prolonged use of covers appeared to result in even higher colony counts, regardless the cleaning agents used to disinfect [20].

A cross-sectional study, conducted to test the efficacy of a device emitting UVC light for disinfecting stethoscope membranes, revealed that the device can efficiently and effectively disinfect stethoscope membranes, even if they are highly contaminated. In the treated one, the percentage reduction in CFU was 94.8 [43].

A wearable device emitting UVC-LED was effective against common pathogens. Since it can be attached to the pocket of the medical coat, the positive aspect of this device is that it can make the disinfection of the stethoscope an automatism repeated after each use [48].

\section{iii. Disposable "Single Patient" Stethoscopes}

In the prevailing COVID19 pandemic, the most recommended, alternative to disinfection, is the use of disposable "single-patient" stethoscope. However, their problem is lacking quality and functionality. The reservations of HCWs, at the settings where this device was introduced, include:

- Poor quality tubing which is often of awkward length

- Hard plastic earpieces

- Poor headset tension

- Single side chest piece with low quality non-tunable diaphragm

In a United States prospective study of $>200$ auscultations, $10.9 \%$ of cardiac pathologies were misdiagnosed by clinicians using such a device [49].

\section{iv. Stethoscopes with Aseptic Barriers (Touch Free Device)}

Disposable barriers that can be applied via a touch-free dispenser (thus preventing contamination with hand pathogens) have been documented to provide robust and efficient solutions to reduce transmission of pathogens via stethoscopes [17].

In comparison to the reported $10.9 \%$ misdiagnosis rate, by use of disposable stethoscope [46], there was $0 \%$ misdiagnosis rate by using high-quality stethoscopes with aseptic barriers [50].

\section{Stethoscope and COVID-19 Pandemic}

"With the emergence of COVID-19, and in its wake, the difficulties in stethoscope hygiene have become disturbingly clear. Just as clear is the persistent importance of the stethoscope and, so, the need to establish new approaches for its safe use".

Robert Gaynes MD, Division of Infectious Diseases at Emory University.

It has been shown that SARS-CoV-2 can survive on steel and plastic surfaces for 72 hours or more [51]. In the prevailing COVID-19 Pandemic, there is significant risk, for the HCWs, during the auscultation process of the patients. A case has been reported of a 32-year-old female 
cardiology resident, at a teaching hospital in Bahrain, who contracted infection from a COVID-19 patients during auscultation [52].

Given the uniqueness of the COVID-19 pandemic caused gravity of problems at global level, mandatory vaccination is typically justified on Milligan grounds [53]. According to John Stuart Mill, the sole ground for the use of state coercion (and restriction of liberty) is when one individual risk harming others [54-Mill]. The HCWs deserve to be given highest priority for the vaccination not only because their job is very sensitive but also their documented potential as disseminator of HAIs.

Electronic Stethoscope, allowing safe distance auscultation, has been introduced by a Spanish Company. Dr. Santiago Figueroa, a thoracic surgeon at the Hospital Clínico Universitario de Valencia, said: "The eKuore electronic stethoscope is proving to be very useful in this crisis. I would say that it offers three main advantages: better protection for healthcare personnel, savings on personal protective equipment and, in addition, high quality auscultation".

However, all this is in experimental stage and multi-center studies are needed for evaluation of claims made by the manufactures.

\section{Keeping the Three Hands of Physicians Clean}

"Stethoscope diaphragms are contaminated with the same pathogens as the hands, and they are capable of transmitting pathogens from patient to patient" [1].

Unfortunately, the stethoscope, carrying the same exact volume and diversity of pathogens as the clinician's fingertips, is a proven vector of disease transmission [19]. Since the patients are continually exposed to unclean stethoscope, the transmission of pathogens from patient to patient, through stethoscope, can undermine the efforts of hand hygiene programs [1].

In a Chilean study, Zuniga et al have argued that hand washing prior to contact with the patient would be less effective if the HCWs use an unclean stethoscope, since there is a possibility of being contaminated with pathogenic microorganisms and vice versa [6].

The three life savior words "Wash your hands" were uttered, for the first time, by Hungarian Obstetrician Ignaz Semmelweis (1818-1865) at the podium of The Vienna Medical Society's lecture hall on the historic day of May 15, 1850. The marvelous discovery was based on his identifying the role of contaminated hands of physicians in spreading fatal infections (Child Bed Fever) to the in-patients, in 1847 [55].

Under "Clean Care is Safer Care", aimed at reducing HAIs, the WHO Guidelines specify "My 5 Moments for Hand Hygiene" which are: before touching a patient, before clean/aseptic procedure, after body fluid exposure risk, after touching a patient and after touching patient surroundings [9]. Likewise, the stethoscopes should be disinfected "before use on each patient" [39]. The resultant synergistic effect would prevent the dissemination of the same pathogens among patients and would certainly reduce the burden of HAIs in healthcare settings.

\section{Conclusion}

"It may seem a strange principle to enunciate as the very first requirement in a hospital that it should do the sick no harm".

Florence Nightingale (1820-1910): Renowned Hospital Reformer.

It is highly deplorable that the advice was not well taken and the "first requirement in a hospital" was ignored. The melancholic reality is that people enter hospital without HAI and leave with HAI.

In view of the negative impact of HAIs on the health and economic status of a community and recognition of measurable (increased LOS, increased strain on Infection Prevention and Control Professionals (ICPs), decreased productivity, over occupancy of beds, more waiting time, involvement in litigation) and immeasurable (negative image building, increased physical and psychological agony of the patients, increased likelihood of complications of additional diagnostic procedures, increased likelihood of spread of MDROs), there is dire need to ratify crucial role of HCWs in the causation of HAIs. Adherence to essential guidelines and well-defined protocols must be ensured. New avenues need to be explored.

The HCWs have been recognized as vectors of infectious diseases [56].

They could affect the transmissibility of infection by two ways: one directly by the role of their hands [57-IFIC] and clothes [58]; and the other by neglect on their part in managing optimal decontamination of the the equipments and procedures. The well-proven additive role of "physician's third hand", to dissemination of pathogens in healthcare settings, is avoidable.

The fittings closing sentence would be thought provoking comments of Dr. David Nash, Founding Dean Emeritus at Jefferson Medical College in Philadelphia.

"Despite all of our hard work, medical care can never be error free. What we must strive for is care that is harm free" [59].

Acknowledgements The authors are highly grateful to Prof. Nicolino Ambrosino Respirologist (Italy) for his scholarly advice to improve the manuscript.

The authors express great appreciation to Dr. Murad Ahmad Khan (Vancouver, BC) for his insightful suggestions and stimulating discussions, throughout the conduct of this study.

Competing Interests The authors declare that they have no direct and indirect financial, commercial, personal/career affiliation with the article, counting any individually held viewpoint that are relevant to their work, to disclose.

Funding: The authors received no financial support, from any quarter, for the research, authorship, and/or publication of this article.

\section{References}

1. Amin A. Keeping the Stethoscope, the Clinician's Third Hand, Clean. Infection Control Today: 2021; 25 (1).

2. Jenkins IH, Monash B, Wu J, Amin A. The third hand: low rates of stethoscope hygiene on general medical services. J Hosp Med. 2015 Jul; 10(7):457-458.

3. O'Flaherty N, Fenelon L. The stethoscope and healthcareassociated infection: a snake in the grass or innocent bystander? J Hosp Infect. 2015 Sep; 91(1):1-7. doi: 10.1016/j.jhin.2015.04.010. Epub 2015 May 1.

4. Alali SA, Shrestha E, Kansakar AR, Parekh A, Dadkhah S, Peacock WF. Community hospital stethoscope cleaning practices and contamination rates. Am J Infect Control. 2020 Nov; 48(11):1365-1369.

5. Whittington AM, Whitlow G, Hewson D, Thomas C, Brett SJ. Bacterial contamination of stethoscopes on the intensive care unit. Anaesthesia. 2009; 64(6): 620-624.

6. Zuniga A, Mañalich J, Cortés R., Estetoscopio o estafiloscopio: Potencial vector en las infecciones asociadas a la atención de la salud [Stethoscope or staphyloscope: Potential vector in nosocomial infections]. Rev Chilena Infectol. 2016 Feb; 33(1): 19-25.

7. PHC4 - Hospital-acquired infections in Pennsylvania January 1, 2005 - December 31, 2005 - Pennsylvania Health Care Cost Containment Council: November 2006; 1-13.

8. WHO-Health care-associated infections FACT SHEET 
9. WHO - WHO Guidelines on Hand Hygiene in Health Care: A Summary. World Health Organization 2009. WHO/IER/PSP/2009.07.

10. Damani N- Manual of Infection Prevention and Control-Oxford University Press 4th Edition 2019.

11. Siegel JD, Rhinehart E, Jackson M, Chiarello L; Healthcare Infection Control Practices Advisory Committee. Management of multidrug-resistant organisms in health care settings, 2006. Am J Infect Control. 2007 Dec; 35(10 Suppl 2):S165-S193.

12. NICE - Healthcare-associated infections. Health and social care directorate Quality standards and indicators Briefing paperNational Institute for Health and Care Excellence 25 June 2015:1-62.

13. Zhang, Y., Du, M., Johnston, J.M, Andres EB, Suo J, Yao H, Huo R, Liu Y, Fu Q-Incidence of healthcare-associated infections in a tertiary hospital in Beijing, China: results from a real-time surveillance system. Antimicrob Resist Infect Control 8, 145 (2019).

14. CDC - Prevention Strategies for Seasonal Influenza in Healthcare Settings.

15. Horiuchi, Y., Wettersten, N., Vasudevan, R.S, Barnett O, Maisel AS. Stethoscope as a Vector for Infectious Disease. Curr Emerg Hosp Med Rep 6, 120-125 (2018).

16. Marinella MA, Pierson C, Chenoweth C. The stethoscope. A potential source of nosocomial infection? Arch Intern Med. 1997 Apr 14; 157(7): 786-790.

17. Vasudevan R, Shin JH, Chopyk J, Peacock WF, Torriani FJ, Maisel AS, Pride DT. Aseptic Barriers Allow a Clean Contact for Contaminated Stethoscope Diaphragms. Mayo Clin Proc Innov Qual Outcomes. 2020 Feb 5; 4(1):21-30.

18. Tschopp C, Schneider A, Longtin Y, Renzi G, Schrenzel J, Pittet D. Predictors of Heavy Stethoscope Contamination Following a Physical Examination. Infect Control Hosp Epidemiol. 2016 Jun; 37(6): 673-679.

19. Longtin Y, Schneider A, Tschopp C, Renzi G, Gayet-Ageron A, Schrenzel J, Pittet D. Contamination of stethoscopes and physicians' hands after a physical examination. Mayo Clin Proc. 2014 Mar; 89(3): 291-299.

20. Wood MW, Lund RC, Stevenson KB. Bacterial contamination of stethoscopes with antimicrobial diaphragm covers. Am J Infect Control. 2007 May; 35(4): 263-266.

21. Schneider A, Tschopp C, Longtin Y, Renzi G, Gaye-Ageron A, Schrenzel J, Pittet D. Predictors of stethoscope contamination following a standardized physical exam. BMC Proc. 2011; 5(Suppl 6): P304.

22. Cohen SR, McCormack DJ, Youkhana A, Wall R. Bacterial colonization of stethoscopes and the effect of cleaning. J Hosp Infect. 2003 Nov; 55(3):236-237.

23. Thapa, S., Sapkota, L.B. Bacteriological assessment of stethoscopes used by healthcare workers in a tertiary care centre of Nepal. BMC Res Notes 10, 353 (2017).

24. Schmidt MG, Tuuri RE, Dharsee A, Attaway HH, Fairey SE, Borg KT, Salgado CD, Hirsch BE. Antimicrobial copper alloys decreased bacteria on stethoscope surfaces. Am J Infect Control. 2017 Jun 1; 45(6):642-647.

25. Smith MA, Mathewson JJ, Ulert IA, Scerpella EG, Ericsson CD. Contaminated stethoscopes revisited. Arch Intern Med. 1996 Jan 8; 156(1):82-84.

26. Zuliani Maluf ME, Maldonado AF, Bercial ME, Pedroso SA. Stethoscope: a friend or an enemy? Sao Paulo Med J. 2002 Jan 3; 120(1):13-15.

27. Bernard L, Kereveur A, Durand D, Gonot J, Goldstein F, Mainardi JL, Acar J, Carlet J. Bacterial contamination of hospital physicians' stethoscopes. Infect Control Hosp Epidemiol. 1999 Sep; 20(9):626-628.

28. Queiroz Júnior JRA, Melo IO, Calado GHDS, Cavalcanti LRC, Sobrinho CRW. Identification and resistance profile of bacteria isolated on stethoscopes by health care professionals: Systematic review. Am J Infect Control. 2021 Feb; 49(2):229237.

29. Uneke CJ, Ndukwe CD, Nwakpu KO, Nnabu RC, Ugwuoru $\mathrm{CD}$, Prasopa-Plaizier N. Stethoscope disinfection campaign in a Nigerian teaching hospital: results of a before-and-after study. J Infect Dev Ctries. 2014 Jan 15; 8(1):86-93.

30. Lee R, Choi SM, Jo SJ, Han S, Park YJ, Choi MA, Kong BK. A quasi-experimental study on stethoscopes contamination with multidrug-resistant bacteria: Its role as a vehicle of transmission. PLoS One. 2021 Apr 22; 16(4): e0250455.

31. Muniz J, Sethi RK, Zaghi J, Ziniel SI, Sandora TJ. Predictors of stethoscope disinfection among pediatric health care providers. Am J Infect Control. 2012 Dec; 40(10):922-925. Epub 2012 Apr 3.

32. Ghumman GW, Ahmad N, Pop-Vicas A, Iftikhar S. Stethoscope Cleaning During Patient Care. R I Med J (2013). 2018 May 1; 101(4):18-20.

33. Zehra D, Iqbal M, Safdar A, Jamil H, Inam SHA, Zahid MA. Awareness Among Healthcare Professionals Regarding Contaminated Stethoscopes as a Source of Nosocomial Infections. Cureus 2019; 11(10): e5968.

34. Sahiledengle B. Stethoscope disinfection is rarely done in Ethiopia: What are the associated factors? PLoS One. 2019 Jun 27; 14(6):e0208365.

35. Boulee D, Kalra S, Haddock A, Johnson TD, Peacock WF. Contemporary stethoscope cleaning practices: What we haven't learned in 150 years. Am J Infect Control. 2019 Mar; 47(3):238-242.

36. Gazibara T, Radovanovic S, Maric G, Rancic B, KisicTepavcevic D, Pekmezovic T. Stethoscope Hygiene: Practice and Attitude of Medical Students. Med Princ Pract. 2015; 24(6):509-514.

37. Salooge H, Steenhoff A. The health professional's role in preventing nosocomial infections. Postgrad Med J. 2001 Jan; 77(903):16-19.

38. Napolitani M, Bezzini D, Moirano F, Bedogni C, Messina G. Methods of Disinfecting Stethoscopes: Systematic Review. Int J Environ Res Public Health. 2020;17(6):1856. Published 2020 Mar 13.

39. Rutala WA, Weber DJ. Best practices for disinfection of noncritical environmental surfaces and equipment in health care facilities: A bundle approach. Am J Infect Control. 2019 Jun; 47S:A96-A105.

40. Knecht VR, McGinniss JE, Shankar HM, Clarke EL, Kelly BJ, Imai I, Fitzgerald AS, Bittinger K, Bushman FD, Collman RG. Molecular analysis of bacterial contamination on stethoscopes in an intensive care unit. Infect Control Hosp Epidemiol. 2018 Dec 18:1-7.

41. Raghubanshi BR, Sapkota S, Adhikari A, Dutta A, Bhattarai U, Bhandari R. Use of $90 \%$ ethanol to decontaminate stethoscopes in resource limited settings. Antimicrob Resist Infect Control. 2017 Jun 15; 6:68.

42. Mehta, A.K.; Halvosa, J.S.; Gould, C.V.; Steinberg, J.P. Efficacy of alcohol-based hand rubs in the disinfection of stethoscopes. Infect. Control Hosp. Epidemiol. 2010, 31, 870872.

43. Parmar RC, Valvi CC, Sira P, Kamat JR. A prospective, randomised, double-blind study of comparative efficacy of 
immediate versus daily cleaning of stethoscope using $66 \%$ ethyl alcohol. Indian J Med Sci. 2004 Oct;58(10):423-430.

44. Holleck JL, Campbell S, Alrawili H, Frank C, Merchant N, Rodwin B, Perez MF, Gupta S, Federman DG, Chang JJ, Vientos W, Dembry L. Stethoscope hygiene: Using cultures and real-time feedback with bioluminescence-based adenosine triphosphate technology to change behavior. Am J Infect Control. 2020; 48(4):380-385.

45. Leprat R, Minary P, Devaux V, de Wazière B, Dupond JL, Talon D. Why, when and how to clean stethoscopes. J Hosp Infect. 1998 May; 39(1):80-82.

46. Messina G, Ceriale E, Burgassi S, Russo C, Nante N, Mariani L, Taddeo L , Lenzi D, Manzi P- Hosting the Unwanted :Stethoscope Contamination Threat-British J Med Medical Res 2014; 4(30): 4868-4872.

47. Lau YF, Wei W, Lau CP. Are stethoscopes risky in COVID19? Postgrad Med J. 2020 Jul; 96(1137):431. Epub 2020 May 21.

48. Messina G, Fattorini M, Nante N, Rosadini D, Serafini A, Tani M, Cevenini G. Time Effectiveness of Ultraviolet C Light (UVC) Emitted by Light Emitting Diodes (LEDs) in Reducing Stethoscope Contamination. Int J Environ Res Public Health. 2016 Sep 23; 13(10):940.

49. Mehmood M, Abu Grara HL, Stewart JS, Khasawneh FA. Comparing the auscultatory accuracy of health care professionals using three different brands of stethoscopes on a simulator. Med Devices (Auckl). 2014 Aug 14; 7:273-281.

50. Kalra S, Garri RF, Shewale JB. Aseptic Disposable Stethoscope Barrier: Acoustically Invisible and Superior to Disposable Stethoscopes. Mayo Clin Proc. 2021 Jan; 96(1):263-264.
51. N van Doremalen, Bushmaker T, Morris DH, Holbrook MG, Gamble A, Williamson BN, Tamin A, Harcourt JL, Thornburg NJ, Gerber SI, Lloyd-Smith JO, de Wit E, Munster VJ. Aerosol and Surface Stability of SARS-CoV-2 as Compared with SARS-CoV-1. N Engl J Med. 2020 Apr 16; 382 (16):15641567.

52. Plexus md App - The Stethoscope: a potential vector for COVID-19?

53. Savulescu J. Good reasons to vaccinate: mandatory or payment for risk? J Med Ethics. 2021 Feb;47(2):78-85.

54. Mill J. On Liberty. (Cambridge Library Collection Philosophy). Cambridge: Cambridge University Press, 2011.

55. Semmelweis I. The etiology, the concept and the prophylaxis of childbed fever. Pest, Hungary: CA Hartleben's VerlagExpedition. 1861.

56. Huttunen R, Syrjänen J. Healthcare workers as vectors of infectious diseases. Eur J Clin Microbiol Infect Dis. 2014 Sep; 33(9):1477-1488.

57. IFIC - Infection Control: Basic Concept and Training. International Federation of Infection Control. 2003, Second Edition.

58. Mitchell A, Spencer M, Edmiston C Jr. Role of healthcare apparel and other healthcare textiles in the transmission of pathogens: a review of the literature. J Hosp Infect. 2015 Aug; 90(4):285-292.

59. SAGE Publications. "Hospital-acquired Infections Inevitable?" Science Daily. 22 November 2006.
This work is licensed under Creative Commons Attribution 4.0 License

To Submit Your Article Click Here: Submit Manuscript

DOI: $10.31579 / 2690-1919 / 199$
Ready to submit your research? Choose Auctores and benefit from:

$>$ fast, convenient online submission

$>$ rigorous peer review by experienced research in your field

$>$ rapid publication on acceptance

$>$ authors retain copyrights

$>$ unique DOI for all articles

$>$ immediate, unrestricted online access

At Auctores, research is always in progress.

Learn more auctoresonline.org/journals/journal-of-clinical-research-andreports 